\title{
LARVAE OF NEOTROPICAL COLEOPTERA XI.: CALLIRHIPIDAE, ARTEMATOPOIDEA
}

CLEIDE COSTA SERGIO A. VANIN 2

\section{ABSTRACT}

Larvae of Callirhipis goryi Castelnau, 1834 and C. scapularis Castelnau, 1834 were collected inside hard logs at the Estação Biológica de Boracéia and in Peruíbe, São Paulo, Brazil; reared adults were identified. Descriptions of the larva and pupa are provided with illustrations.

\section{INTRODUCTION}

Callirhipis Latreille, 1829 was considered for many years as belonging to the camily Rhipiceridae. Crowson (1967) characterized the Callirphipidae within the Rhipiceroidea. In 1973, the same author transferred Callirphipidae from Khipiceroidea to Artematopoidea, pointing out that this family "constitutes a very homogeneous group"... and that "the known larvae are all woodborers of wire-worm-like shape with a characteristic terminal operculum formed by the 9th abdominal tergite".

Callirhipis comprises about 100 species found in all main zoogeographical regions; 30 in the Neotropical Region and 11 in Brazil.

Van Emden $(1931,1932)$ published several descriptions of Callirhipini larvae, some of them from Central America, but up to now there are no larvae known from the Brazilian region. According to van Endem's (1932) key, Callirhipis goryi and C. scapularis are keyed out near C. valida Champion, from Costa Rica.

Gardner (1931) presented the main characteristics of the Callirhipis larvae: "Body cylindrical, very hard and corneous. Setae very sparse. Ocelli not evident. Antennae retractile, small, with two well-developed corneous basal joints and a minute unisetiferous apical papilla which may perhaps represent a third joint. Abdominal segment 8 with an oblique striate groove on each side. Segment 9 forming a sub-vertical operculum; posterior end of the body with a truncate appearance".

\section{Callirhipis goryi Castelnau, 1834}

(figs. 1-20)

Length 40 to $45 \mathrm{~mm}$. Width 4 to $5 \mathrm{~mm}$. Cylindrical, general shape wireworm-like; general color yellowish or reddish brown with transverse stripes darker, dorsal surface of head and first thoracic segment dark-brown, ventral surface of thoracic segments and legs darker, thoracic segments 2-3 and abdominal segments 1-6 with a transverse, striate, posterior segmental stripe dark-brown, abdominal segments 7-8 gradually darker towards the posterior margin, and segment 9 black. Dorsal surface of thoracic segments 1-3 with asperities decreasing in number from the first to the third segment. Abdominal segment 7 with a pair of deep foveae; segment 8 with a pair of striate grooves and posterior margin with two pairs of small spines; segment 9 operculated, slightly convex, strongly punctured and with several minute setae.

1. Museu de Zoologia da Universidade de São Paulo. With partial aid from "Fundação de Amparo à Pesquisa do Estado de São Paulo" (Proc. 38-Zoologia 81/1932-1 and 82/2295-8). Pesquisadora do Conselho Nacional de Desenvolvimento Científico e Tecnológico.

2. Departamento de Zoologia da Universidade de São Paulo. With partial aid from "Fundação de Amparo à Pesquisa do Estado de São Paulo" (Proc. Biol. 80/0540). 
Head hypognathous, deeply pigmented, heavily sclerotized, partially retracted into thorax, densely punctulate and with several minute setae. Epicranial suture present; epicranial stem long; frontal arms Y-shaped. Ocelli absent.

Labrum (fig. 9) free, transverse, anterior margin sinuous with median scissure, covered with 4 pairs of strong setae and one stronger seta on each side. Epipharynx (fig. 10) concave and smooth in the middle, with a tuft of strong setae on each side. Gula well developed, with two gular sutures.

Antenna (fig. 5) very small, two-segmented, first segment short, second twice as long as first and with a minute unisetiferous subapical sensory appendix.

Mouthparts retracted. Mandibles (figs. 6-8) symmetrical, palmate, with tridentate apex and two teeth, one on ventral surface and other on dorsal margin; internal part concave, spoon-like; articulatory areas formed by two ventral condyles and dorsal acceptabulum. Maxillae and labium (fig. 4) forming a compact unit. Maxillae very wide, with mala rounded, articulated to stipes and with internal uncus-like small projection and several long setae apically. Maxillary palp three-jointed, palpifer joint-like, bearing one long seta. Cardo transverse. Maxillary articulating area well developed. Labium with transverse mentum; submentum triangular, not reaching the base of stipes; and ligula quadrate, well sclerotized. Labial palpus two segmented, the basal segment almost globular, the second very small.

Head and thorax (figs. 1-3) approximately as wide as the abdomen. Dorsal surface of thoracic segments 1-3 covered with minute asperities. Thoracic spiracles on mesothorax. Legs (fig. 1a) very short, all about equal size, five segmented including tarsunguli; claws bisetose.

Abdomen cylindrical, with 9 segments; with 8 pairs of biforous spiracles similar in size. Tergite, pleurites and sternite fused to form a cylinder. Segments 1-7 smooth, finely and scarcely punctulate and with a few minute setae and a very short impressed line near the anterior margin. Tergum 7 with a pair of deep foveae. Tergum 8 with an oblique striate groove on each side forming an angle of about $80^{\circ}$ and a pair of small spines on the posterior margin. Abdominal segment nine (figs. 11-17) forming an oblique operculum with lateral margins raised; posterior end of the body truncate; surface dense and strongly punctulate, with minute setae and two very small tubercles posteriorly. Anal opening transversely curved.

Pupa (figs. 18-20). Adecticous, exarate. Abdomen elongate, slender. Frons, pronotum and abdominal tergite covered with numerous setiferous asperities. Gin traps absent. Abdominal segment 9 operculate, oblique.

\section{MATERIAL EXAMINED}

BRAZIL. São Paulo: Peruíbe, 1 larva reared to adult, 29.vi.1981, Exp. MZSP col. (MZSP). Salesópolis, Estação Biológica de Boracéia 1 larva reared to adult; 12 larvae fixed, 22-25.x.1982, Exp. DZUSP col. (MZSP).

Biological note. Larvae from "Estação Biológica de Boracéia" were collected inside hard logs of a Lauraceae, probably of the genera Nectranda or Ocotea.

\section{Callirhipis scapularis Castelnau, 1834}

Four larvae collected by C. Costa, 12-14.xi.1969, inside hard logs at "Estação Biológica de Boracéia", Salesópolis, São Paulo, Brazil, were kept in the laboratory and three of them reached the adult stage.

We have noticed no important differences between the larva of this species and those of $C$. goryi.

\section{DISCUSSION}

Larvae of Callirhipis goryi, C. scapularis (Brasil) and C. valida (Costa Rica) share the following characters: tergum 7 with a pair of deep foveae; tergum 8 with two divergent striale grooves forming an angle of approximately 

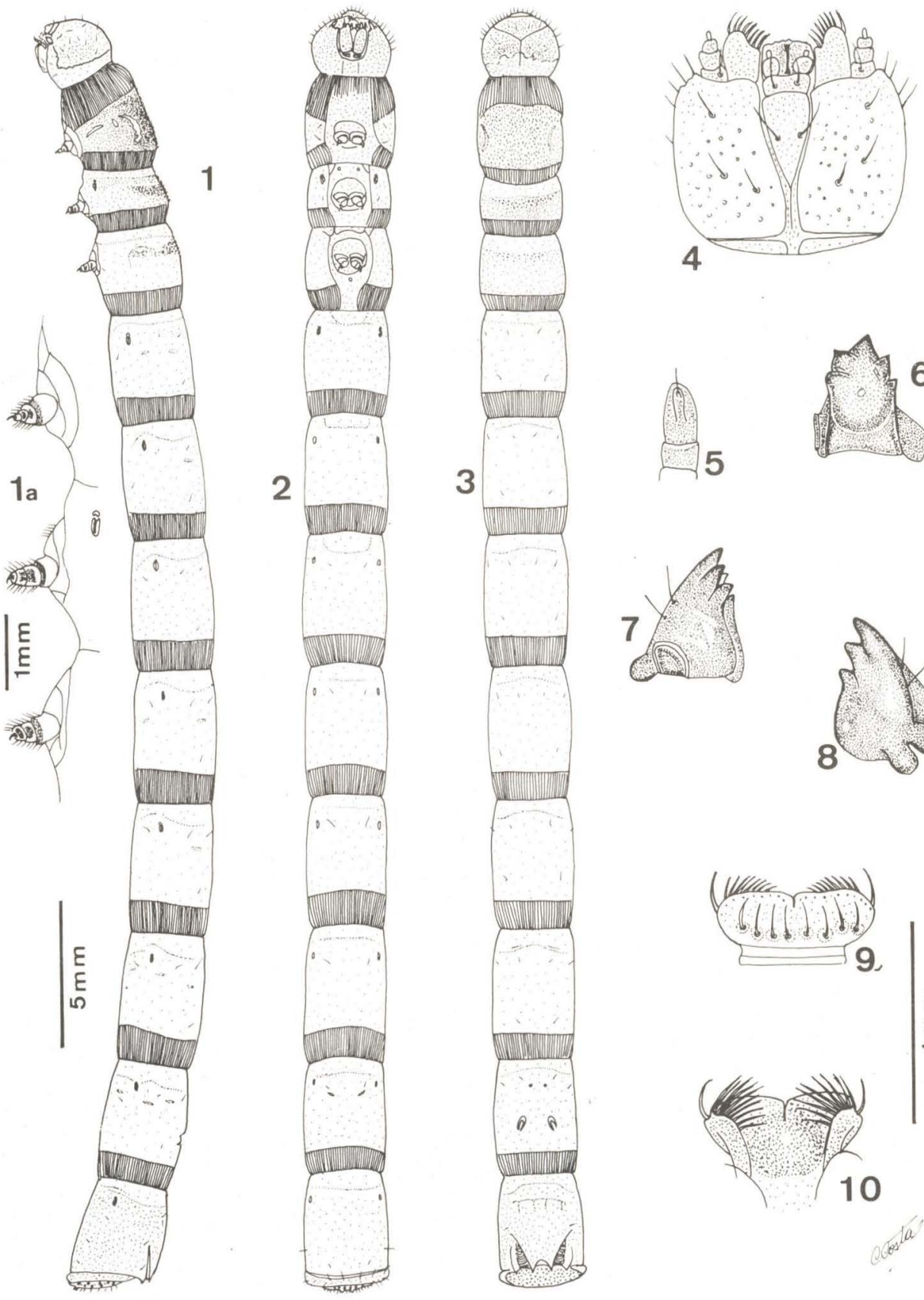

3
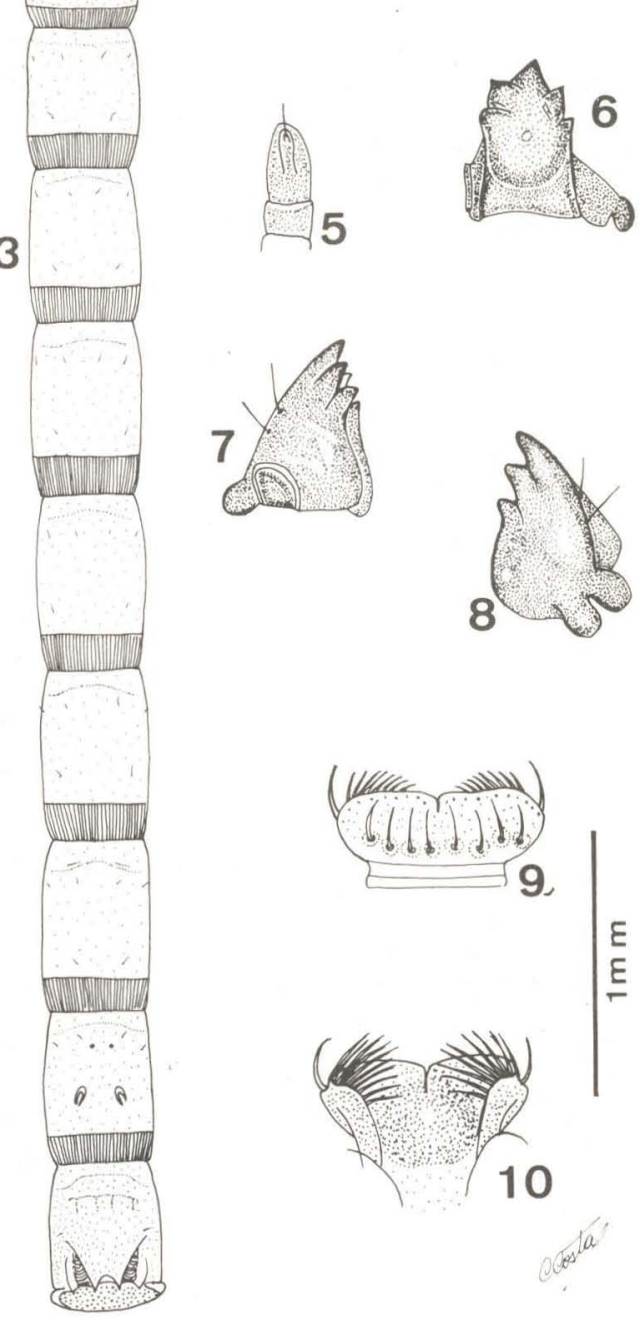

Callirhipis goryi, 1-3, lateral, ventral and dorsal views; 1a legs; 4, maxillae and labium; 5, antenna; 6-8, mandible; 9, labrum; 10, epipharynx. 

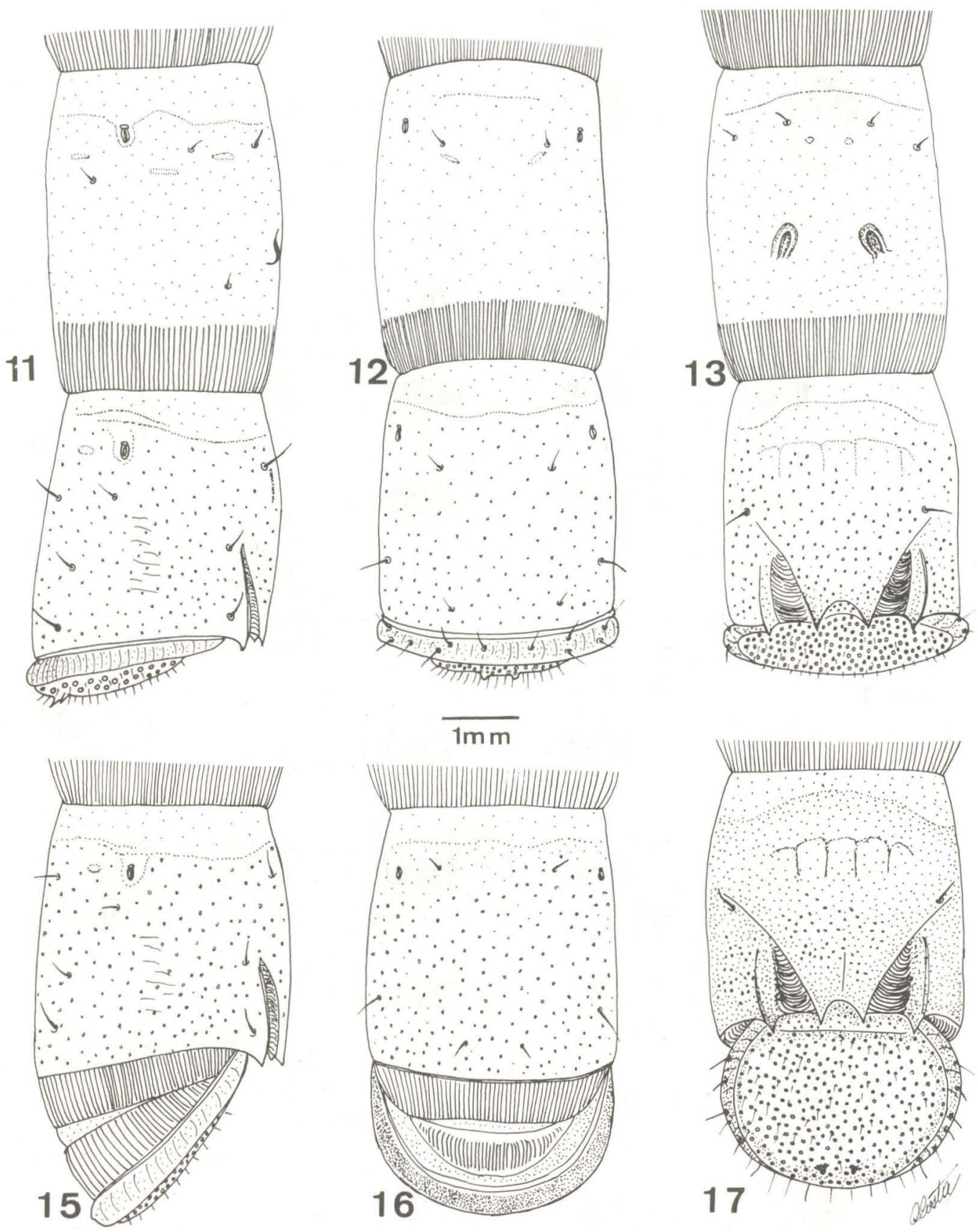

Callirhipis goryi, 11-13, abdominal segments; 7-9, lateral, ventral and dorsal views; 15-17, abdominal segment 9 distended, lateral, ventral and dorsal views. 


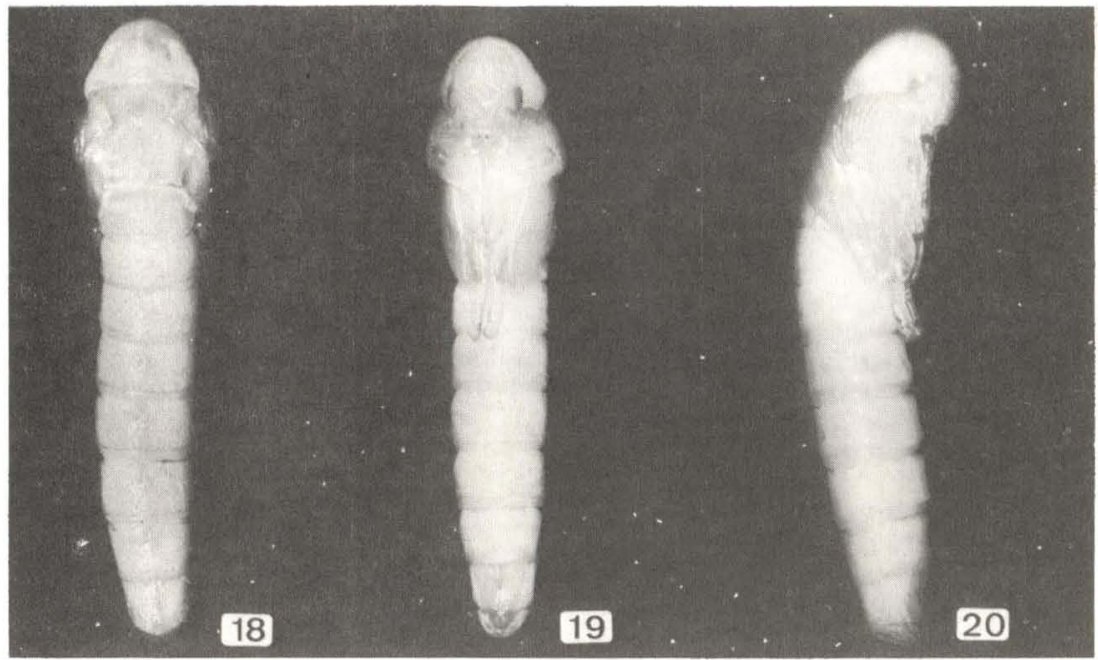

Callirhipis goryi, 18-20, Pupa, dorsal, ventral and lateral views.

$80^{\circ}$ and with a pair of small spines on the posterior margin; operculum slightly convex, with lateral margin raised.

C. goryi and C. scapularis differ from $C$. valida by the apex of the submentum not reaching the base of stipes (reaching in C. valida) and by the anterior margin of the labrum sinuous but not forming lobes (with four lobes in C. valida).

\section{ACKNOWLEDGMENTS}

We are grateful to Dr. R. A. Crowson from the Department of Zoology of the University of Glasgow for reading and commenting the manuscript and for his useful suggestions. We thank Maria Dolores G. C. dos Santos from the Instituto de Pesquisas Tecnológicas, S. Paulo for the Lauraceae identification and Giro Pastore for the photographs.

\section{REFERENCES}

Castelnau, F. L. N. C. Laporte, Comte de, 1834. Monographie du groupe des Rhipicérites (coléoptères pentamères). Ann. Soc. ent. Fr. 3: 225-370.

Crowson, R. A., 1967. The Natural Classification of the families of Coleoptera, 214 pp., E. W. Classey Ltd., Middlesex, England.

Crowson, R. A., 1973. On a new Superfamily Artematopoidea of polyphagan beetles, with the definition of two new fossil genera from the Baltic Amber. J. nat. Hist. 7: 225-238.

Gardner, J. C. M., 1931. The early stages of two species of Rhipiceridae (Sandalidae) from India. Trans. ent. Soc. London 79(3): 427-430, 1 pl.

Van Emden, F., 1931. Zur Kenntnis der Sandalidae XI-XVI. Ent. Bl., Berlin 27: 49-59; 107-116; 145-152, 1 pl., 5 figs.

Van Emden, F., 1932. Die Larven der Callirrhipini, eine mutmassliche Cerophytum - Larve und Familien-Bestimmungstabelle der Larven der Malacodermata-Sternoxia-Reihe (Coleoptera), Bull. Ann. Soc. ent. Belgique 72: $119-259,3$ pls. 